

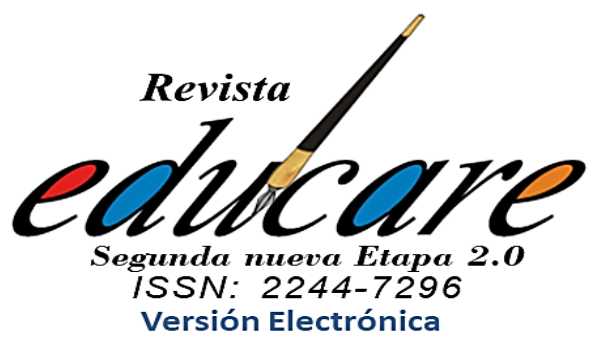

\title{
DEL PLACER DE LEER Y EL JUEGO LITERARIO
}

\author{
AROUND THE PLEASURE OF \\ READING AND LITERARY PLAY
}

\section{Resumen}

El maestro tiene el compromiso ético y pedagógico de asumir la lectura como un arte, sea literaria o no pues actualmente debe valorarse la lectura desde un estadio menos excluyente. El mediador de la lectura debe de igual manera asumir el salón de clases como un espacio creativo en tanto diversión y felicidad colectiva, todo ello sabiendo que los lectores son tan diversos como lo es la literatura, de allí justamente los infinitos gustos por libros. La lectura en el aula conlleva procesos de profunda significación, la primera de ellas es la formación y ello no significa que el docente sea el único en enseñar pues el aula es el escenario en el que todos nos ayudamos y más aún donde todos somos maestros según sus capacidades y según las fortalezas. La lectura, finalmente es el antídoto más cónsono para relacionarse en un entorno en el que una parte muy importante de la población mundial se aleja hasta de sí mismo.

Palabras clave: Lectura, placer, literatura, educación.

\begin{abstract}
The teacher has the ethical and pedagogical agreement to assume the reading as art, be it literary or not; currently, the reading must be valued from a less exclusive stage. In the same way, the mediator of reading assumes the classroom as a creative space while fun and collective happiness, all this knowing that readers are as diverse as literature, hence precisely the infinite tastes for books. The classroom reading involves profound significance processes. The first is personal development, and this does not mean that the teacher is the only one to teach because the classroom is the setting in which we all help each other and even more so where we are all teachers according to our capabilities and according to strengths. Reading, finally, is the most harmonious antidote for being in contact in an environment in which a very important part of the world population even distances from themselves.
\end{abstract}

Keywords: Reading, literature, pleasure, education. 


\section{Introducción \\ Un niño no es una botella que hay que llenar, sino un fuego que hay que avivar. Michel Eyquem de Montaine} No hay espectáculo más hermoso que la mirada de un niño que lee. Günter Grass

Cuando el maestro asume con dedicación y esmero el arte de la lectura es posible que se llegue a ese evento tan importante como es el placer de leer, sobre todo pensando que dicho acto se llevará a cabo con todos los sentidos. De ese modo, el recorrido de cualquier alumno por espacios escolares, lejos de sentir un encierro clásico le proporcionará libertad y agrado para aprender. Este aprendizaje, lejos de representar la aprehensión de los textos en tanto oficio obligatorio y aprobatorio conlleva más bien la afectuosa posibilidad de asistir a lo que el maestro Luis Beltrán Prieto Figueroa llamó "la magia de los libros y disfrute de su compañía" (p.27).

Quien trabaje en función de la formación de la lectura, independientemente que sea maestro o no, asumirá principalmente que el ingrediente esencial allí será el deleite y el placer provocado por los distintos libros y lecturas recomendadas, siendo la verdadera misión en ese proceso formativo con miras a la adultez. No obstante, el docente estará en la capacidad de suministrarle títulos y autores cuya obra propicie un incentivo o estímulo, esto no quiere decir que se igualen las épocas de formación, pues la del maestro y el niño son formaciones en tiempos diferentes y una de las limitantes en ocasiones es la contraposición de generaciones; el docente debe saber que un lector actual lo más probable es que reclame lecturas actuales o por lo menos de su contexto real y más próximo.

La escuela tradicional, en su mayor parte se ha dedicado a enseñar más para sumar conocimientos que para el disfrute de los libros y la lectura, como se dijo anteriormente, esa forma tan ceñida de llevar a cabo la literatura sólo conduce a cuestionarios y preguntas que no dan libertad, sino más bien cercenan la posibilidad de una manifestación subjetiva por parte del alumno.

El placer del texto, contradictoriamente, no es algo cuya prioridad haya sido la misión de muchos maestros de ayer y hoy, y es por eso que el libro en ocasiones causa una suerte de aversión en el niño, cuando ocurre lo contrario Roland Barthes sostiene lo siguiente: 
Este hombre sería la abyección de nuestra sociedad: los tribunales, la escuela, el manicomio, la conversación harían de él un extranjero: ¿quién sería capaz de soportar la contradicción sin vergüenza? Sin embargo, este contra-héroe existe: es el lector del texto en el momento en que toma su placer (p.12).

Al nacer ese sujeto, envuelto por el placer, permite tomar direcciones alternas en torno a temas y cotos sociales, se puede decir que una capa le ha sido desprendida a ese sujeto ahora con nuevos rasgos y oportunidades de enfrentarse al mundo real y sin variantes de otros.

En ese sentido, el placer del texto no puede darse desde las aristas del otro, en este caso desde la visión personal y subjetiva del docente, así, el placer por la lectura se da desde el individuo bien por grietas o fisuras que él mismo abre desde ese espacio comunicante entre lector y texto. Después de eso, el lector asume la lectura (dado el caso que sea de su agrado) al punto de adoptarla, en ese preciso momento se ha construido un espacio y "El placer del texto es similar a ese instante insostenible, imposible, puramente novelesco que el libertino gusta al término de una ardua maquinación haciendo cortar la cuerda que lo tiene suspendido en el momento mismo del goce." (Barthes, 2008, p.15). Por ende, cuando sucede esto sencillamente puede decirse que el placer ha atrapado al lector, llevándolo a estadios en los que puede reflexionar y hasta rehacer aquello que ha leído.

\section{La lectura y los sentidos}

La generosidad primordial que ofrece el placer de la lectura a las personas o lectores, indudablemente es que ésta los acerca a un mundo que les pertenece sin miedos ni ataduras, además que cada texto bien concebido desde sus sentidos será una inversión a largo plazo en su universo léxico, semántico y psicológico. Y este placer le permite al niño el contacto con culturas, personajes y hechos que escapan de su contexto social inmediato. La lectura, como ha sido planteada desde la escuela, permite el viaje imaginario y la fantasía gracias al poder de la palabra creadora.

El lector que se maneja bajo la tónica del placer es un ser que se deja seducir por el texto, le ha visto ese lado llamativo invitándolo al disfrute de sus palabras, de sus frases y de la visión de mundo. Es así como el texto, podría decirse, le ha mostrado al sujeto sus "zonas erógenas" (Barthes, 2008, p.18) permitiéndole dar un vistazo a una pequeña parte y desde allí capturar y al individuo catapultándolo a ese lugar de encantamiento y embeleso. 
Esa pequeña muestra desde el texto, del cual se ha ido enganchado el sujeto representa una parte de ese constructo total que es el relato, para Barthes (2008) es “...un develamiento progresivo..." (p.18), que, a un ritmo y sin importar que sea lento o rápido, le permite al sujeto ir apoderándose de la obra y degustar el sabor de sus palabras cuando las despoja de inquietudes y curiosidades presentes en su mundo subjetivo. El ser humano se nutre, percibe y aprende a través de todos los sentidos, es por ello que, así como los alimentos satisfacen necesidades fisiológicas, de igual modo la lectura tiende a alimentar el intelecto y al ser del lector.

Si el texto de placer es el que conduce a un estado de alegría y elevación de los estados anímicos, no puede entonces pensarse el texto con ataduras u obligaciones, pues esto implica un principio reduccionista y allí pierde forma tanto el texto como el lector. En definitiva, lo que se quiere es lo contrario, que cada segundo sea de estrechas confluencias e imbricación entre lector y texto al punto de familiarizarlos con elementos de mucha consistencia empezando con el placer.

El placer puede atrapar al lector en cualquier etapa de su vida, tal como lo asume Savarin (1996) al momento de hablar del gusto por los alimentos, asegura que "el placer de la mesa se siente a todas las edades, en todas las condiciones, en todos los países y todos los días” (p.9), siendo esto una clara analogía la cual nos permite descifrar que nunca será tarde para asumir el gusto por la lectura, sin importar el tiempo, el espacio y las circunstancias.

Este placer del cual se ha venido hablando en torno a los textos no siempre es una constante en el proceso de la lectura, todo lector tiene el derecho a la renuncia cuando así lo crea conveniente, de algún modo la lectura no le garantiza al lector que sea agradable hasta el final. En ese camino, se da lo que Barthes (2008 denomina “...la deriva del texto...” (p.29) y como todo alejamiento, el lector ha tomado un nuevo derrotero, el de abandonar dicho acto pues su principio de libertad le ha llevado a tomar esa decisión. En consecuencia, es necesario resaltar que hasta la mejor obra de la literatura universal puede pasar por tediosa y aburrida para un lector, su inclusión en un canon no será suficiente para calar en el sujeto, es justo por eso que Schücking (1969) sustenta que "no hay herencia en el arte, y el puro hecho de existir no concede derechos" (p.100), superando así cualquier paradigma clásico contrario a la voluntad de un lector con principio de autenticidad.

Después de esa renuncia al texto, o entrega si lo logra atrapar por completo, se confirma la lectura como ese acto liberador en el que un individuo desarrolla posiciones críticas ante el 
mundo, actitudes de tolerancia y aceptación con las cuales se asumen nuevas visiones del mundo en base a derechos y deberes que son finalmente los pilares de todo ser. Esa abdicación a patrones clásicos de lectura, literatura y educación pasa por el tamiz del sentido en tanto autonomía del lector, ya lo decía Greimas (1973) la obra de arte -y acá hace énfasis en la obra literaria- "son únicamente pretextos; que solo tiene el sentido -o los sentidos- que nosotros les prestamos" (p.2). Precisamente por esa especie de autogestión que desarrolla el lector donde llega a superar todo lo planteado por el creador de dicha obra, fenómeno que posibilita incluso la recreación y la reinvención después de haber leído bajo la impetuosa vorágine de la pasión y no de una estéril presión conducente al fracaso escolar del arte de leer.

El placer de leer lleva al sujeto a ser el personaje principal de su propia experiencia, coadyuva también a que el lector no sea pasivo, ello hace despertar sus inquietudes y a preguntarse desde su interior acerca de eventos y situaciones que le rodeen. La lectura va desarrollando facultades en el individuo, por ejemplo, hay relatos que realzan lo minucioso y cauteloso en quien las lea, los cuentos de hadas facilitan la imaginación y la fantasía, sobre todo en los niños que se sumergen en mundos paralelos y desde allí narran sus experiencias. Todo ello, incluso puede conducir a ese sujeto a la escritura, y en vista de eso, Margot Carrillo Pimentel sostiene desde su perspectiva que:

Leer, como narrar, es un acto de rememoración, de reconstrucción de lugares, paisajes, personajes y de un tiempo que ha pasado, pero que, gracias a la configuración narrativa, puede recontarse, revisitarse, volverse a vivir. De tal modo, hablar de la lectura a través del relato se convierte en un doble acto de interpretación: se recupera y se cuenta, se lee y se escribe, se rememora y se revive la experiencia. Es como si leer y escribir fueran acontecimientos equivalentes: modos de habitar e interpretar el mundo, otro mundo; maneras de darle sentido a lo ya vivido, a lo imaginado o a lo que puede estar por llegar (s.p).

Naturalmente el texto, el lector, el escritor y todos los implicados en el multicolor mundo de la lectura encuentran una salida a la monotonía, un placer de vivir experiencias al lado de personajes literarios que se emparentan e identifican con los lectores, viajando entonces a lugares posibles e imposibles pues la literatura de ficción así lo permite por no poseer límites en todas sus vertientes. Es así como Trías (1991) señala que "el límite es un espacio tenso y conflictivo de mediación y enlace" (p.16), siendo allí donde el lector libra una sana y hasta artística disputa en 
la que va emanando maniobras contundentes hacia un centro de sentidos presentes en la obra literaria que lee. Por ende, al darse este fenómeno hermenéutico conducente a una justa independencia del lector, germinará en el aula de clases cierto temor por parte de algunos docentes tradicionalistas quienes calificarán de subversivos a todos aquellos quienes no piensen ni analicen los textos literarios tal cual ellos lo dictaminen, es allí donde ha nacido el ser que no limita el conocer.

\section{Lectura, literatura y juego}

Cuando la literatura se ha asumido desde la experiencia y se ha comenzado a formar el individuo, se despliegan amplias posibilidades desde el texto, una de ellas es el juego, siendo algo que está ligado al ser humano desde que nace y a lo largo de la vida estará inserto en diversos tipos de juego. En la literatura existen múltiples formas de jugar, más si es placentera y gozosa como ya se ha resaltado con anterioridad. Por ende, la imaginación, cuyo principio abarca diversos estadios, resulta "un término de indefinida y polivalente significación" (Lapoujade, 1998, p.15); y más cuando es acompañada del juego de palabras que normalmente se presentan en las rimas, poesías, adivinanzas, trabalenguas, estribillos y canciones de cuna, llevando en sí el germen de procesos que permiten el juego en la literatura y con ello la motivación para que los niños vivan la ilusión, la utopía y la creatividad.

El juego está presente en todas las sociedades, desde la infancia el sujeto tiene la oportunidad de acceder a formas particulares de eventos lúdicos que su contexto le ha dado como legado y a partir de allí comienza un proceso de socialización típico en todo grupo humano. Visto de este modo, y tomando en cuenta que el juego es de carácter universal, se podrá decir en palabras de Huizinga (2000) que "la cultura humana brota del juego -como juego - y en él se desarrolla" (p.7), al punto de que su carácter estético emanará una belleza tal que Schiller (1968) hablara de un estado pleno del hombre en que "es precisamente el juego y sólo el juego el que realiza íntegramente lo humano" (p.71), prueba de esto es que hoy día se habla de juegos desde diferentes espacios, por ejemplo, los juegos deportivos, educativos, lingüísticos, políticos, sexuales y culinarios entre otros.

En ese sentido, podría asumirse que el texto, al igual que el juego, provienen de la cultura, y por ende todo texto, ubicado en un espacio social, cumple con una función determinada como la de informar y ubicar al lector en un tiempo y un contexto determinado. Es por ello entonces que Lotman (1999) propone la función más importante del texto como lo es su 
“papel social” (p.163), así pues, el texto crea un puente de interconexión entre el lector y su mundo de tejidos textuales en la cual se ve reflejada su cultura y sus valores esenciales, para el autor citado esa cultura "es un conjunto de textos o un texto construido de manera compleja" (p.167).

Por otra parte, se tendrá presente que no solamente el hombre juega, también lo hacen los animales, cuando se observa a los gatos, perros, monos y delfines se puede notar la forma en que éstos se entretienen haciendo piruetas, saltando e incluso interactuando al lado de las personas que se desempeñan como sus dueños y amigos, como lo dice el viejo adagio 'el perro es el mejor amigo del hombre' y no en vano han sido compañeros de personajes en historias y relatos. Es posible que los animales jueguen por instinto y no racionalmente como lo hacen los seres humanos, en palabras de Huizinga (2000) se dirá que "los animales no han esperado a que el hombre les enseñara a jugar" (p.11) y esto a su vez lleva a plantearse la posibilidad de que fue el hombre quien vio jugar a los animales y desde allí ha florecido el juego en la humanidad hasta la evolución que hoy día se conoce.

En consecuencia, se asume el juego con orígenes compartidos desde los seres humanos (racionales) y los animales (irracionales), y en ambas permite la relación de unos y otros con sus respectivos semejantes. En el caso de los seres humanos, aunado al aspecto fundamental de este trabajo que es la lectura y los textos literarios, puede resaltarse que el elemento lúdico más importante es el lenguaje, cuyo uso permite las relaciones interpersonales en un tiempo y un espacio determinado. Tan es así, que Tusón (1989) ve en el lenguaje "la facultad que mejor nos define como seres humanos" (p.12) y su poder en tanto amplitud del ser nos lleva a habitar una casa común cuyo lujo mayor es la relación con el otro, más aún cuando esa cercanía se da por medio de un diálogo literario o de lecturas compartidas.

Tomando en cuenta que el juego se encuentra en todos los espacios y circunstancias del individuo, la literatura y su función lúdica harán acto de presencia como una extensión de las grandes capacidades del hombre para generar infinitud. Así, esos juegos dialógicos presentes en las obras para niños y jóvenes se van insertando en el universo léxico-semántico del ser y es por ello que sirven para entender el mundo y darle un sentido pleno desde la subjetividad del lector. La literatura, dentro de todas sus posibilidades y alcances aclara panoramas que muchas veces las historia, la filosofía y las ciencias exactas se ven limitadas de expresar, es justo allí donde la ficción emana verdades desde otros caudales discursivos propios de novelistas, cuentistas, poetas 
y dramaturgos. Esta verdad, brota por una parte del texto en tanto creación del artista, pero por otra parte es el resultado de un juego al cual Zúñiga García (1995) consideró como “el centro que articula toda reflexión estética" (p.199); y es esa la principal pretensión del discurso literario, seducir a su lector mediante juegos de sentidos, de esa manera las conversaciones en torno al arte serán inconmensurables pues cada persona tendrá su propia interpretación.

Esta exégesis en torno al arte literario, permitirá el acuerdo para alcanzar un tipo de verdad consensuada, producto de toda discusión la cual servirá para superar un obstáculo epistemológico de lectura y es el señalado por Smith (19992) quien dice "el primer paso hacia la comprensión es que muchas preguntas permanecen sin respuesta" (p.6), y esto es precisamente la magia de la lectura, hacer que un lector exprese en demasía aquello que ha leído o sencillamente callar pues ambos son derechos lúdicos de quien ha realizado una transacción textual.

Un elemento común que caracteriza a la literatura, la lectura y el juego es su principio de libertad, en ese sentido, quien escribe lo hace como mejor lo cree conveniente, quien lee de igual modo lo hace cuando guste y quien juega escoge el momento determinado. Es por esta razón que Huizinga (2000) expresa lo siguiente: “Todo juego es, antes que nada, una actividad libre. El juego por mandato no es juego" (p.20), y si se transfiere esta definición a la lectura será posible decir que quien imponga la lectura como obligación o castigo de algún modo cierra el juego impidiendo que el lector ingrese a ella de manera activa, alegre y creativa.

Cuando el niño y el joven juegan desde la literatura, construyen mundos paralelos y desde allí construyen su discurso y se transforman en sus héroes viviendo sus propios mundos y llevando a cabo batallas similares a las narradas en los textos, incluso para él tiene un principio de seriedad, si un adulto lo cuestiona o le dice que es mentira, éste se molestará y es muy posible que se enfrente a sus mayores por defender una idea.

Ahora bien, con lo anterior se constata que el juego es infinito, cuando las reglas son establecidas por el jugador éste se va del mundo real creando otros que resultan una variante de lo que lee y se desdobla en sus personajes favoritos. Todo ello favorece al niño, al adolescente y al joven al punto de favorecer su inteligencia pues "incrementa el desarrollo de lo afectivo y lo cognitivo" (López, 1997, p.21).

Otro punto convergente a la hora de hablar de literatura y juego es su carácter real o ficticio, ninguno de los dos aspira tener asidero en el mundo de la realidad, al respecto, Cervera (1992) comenta que "ni el juego intenta producir una acción verdadera, ni la literatura pretende 
reproducir la vida real, tal como es" (p.196), lo que afianza más el principio de seleccionar el camino a seguir cuando se lee ya que no está predeterminada una verdad o una mentira. Esto le permite al sujeto jugar con los finales, incluso cuestionar lo que el autor dice ya que la obra en manos del lector se convierte en otra después de ser leída, interpretada y digerida a su manera. Después de todo, la obra literaria interviene en el universo de sentidos del lector cumpliéndose lo que Girard llamará "modelo mediador del deseo” (9), estructurándose así las ansias personales a partir de las justas, sutiles y perspicaces propuestas estéticas presentes en obras de arte.

En la narrativa para niños y jóvenes lo más importante es que ésta propicie la imaginación e invite al lector a jugar desde su composición literaria. Desde esa perspectiva, estará exaltada desde las humanizaciones, exageraciones, comparaciones, onomatopeyas, epítetos, repeticiones, diminutivos, aumentativos y otros que al final no sólo conforman la materia prima del hecho literario, sino que son formas de jugar con el lenguaje y ello a su vez invita al niño a que participe de esa lúdica literaria. Por todo ello, diremos que el lenguaje literario, más que un lenguaje encriptado es lo que Fromm (1974) designa como "lenguaje simbólico -aludiendo que- es un lenguaje por derecho propio, más aún, el único lenguaje universal que haya producido la humanidad" (p.5); puesto que las figuras del pensamiento literario son utilizadas en la literatura universal por los escritores a lo largo de la historia.

El lenguaje figurado o lenguaje literario, no es el lenguaje de la cotidianidad, por eso quien accede a él por medio de la lectura se inserta en una descripción distinta de las cosas y por ende a un juego del lenguaje y a la lengua misma que finalmente es la que permite moldearla y jugar con las palabras. En un sentido amplio, Wittgenstein (1988) llama juego del lenguaje "al todo formado por el lenguaje y las acciones con las que está entretejido" (p.25); y si ese juego remite a una acción, precisamente la literatura, que es un tejido construido en función de descripciones e imágenes, lleva al lector a moverse dentro de cada tropo literario incluso apoderándose de palabras y frases que a éste le parezcan agradables o por lo menos le sean significativas su visión de mundo.

Las posibilidades para jugar con el lenguaje son infinitas, quizá una lengua tenga un número aproximado de palabras, pero la combinación entre ellas es lo que no tiene límites, con ellas se elaboran a diario frases y diálogos desde las circunstancias de cada sujeto; de esta manera, fusionando los horizontes del juego y la lectura se alcanzará más fácilmente el placer por ella. No obstante, el autor de una obra juega con las palabras creando mundos y personajes 
con cualidades que a otro ser no se le hubieran ocurrido. En toda cultura existen lenguajes técnicos y lenguajes coloquiales lo cual hace diferente a cada sociedad, esto lleva a Wittgenstein (1988) a denominar cada rasgo de una lengua como:

Un suburbio de nuestro lenguaje. (¿Y con cuántas casas o calles comienza una ciudad a ser ciudad?) Nuestro lenguaje puede como una vieja ciudad: una maraña de callejas y plazas, de viejas y nuevas casas, y con casas con anexos de diversos períodos; y esto rodeado de un conjunto de barrios nuevos con calles rectas y regulares y con casas uniformes (p.31).

Visto esto, se puede constatar que cada juego literario, cada combinación desde el poder creativo del sujeto, se va anexionando a esa fuente o raíz común que es la lengua o formas comunicacionales de cada cultura y como tal ese sistema y los horizontes del lector crecen, tal cual crece la ciudad antes descrita por el autor abordado en la cita.

Si se plantea la actividad de lectura como tarea con carácter lúdico se podrá ganar adeptos desde ese acto tan grandioso que es leer, sus cimientos serán el gozo y la alegría por parte de quien se fusiona al lado de la obra y la eleva como máximo estandarte en el proceso de encuentro con el libro. A decir de Carrillo Pimentel y Carrillo (s.a) se podrá precisar que:

Hay libros que nos son indiferentes, otros nos conmueven; algunos nos incitan al diálogo, deseamos compartirlos, interpelarlos; con ciertos textos nos identificamos, otros los padecemos, los odiamos y los que más nos tocan emocional o intelectualmente, pueden llevarnos hasta las lágrimas o la risa o a la propia escritura. (s.p).

Es por ello que el libro, más que un objeto a reposar en bibliotecas, estantes y lugares apartados de la casa tiene que dejarse en las manos de los niños y jóvenes para que estos le den vida a ese manantial que corre desde cada página hasta las venas mismas del sujeto. Tomando en cuenta la lectura, indistintamente que sea infantil o juvenil, tiene que ver con varios factores descritos anteriormente como lo son la formación, la experiencia, el placer y la alegría. Es necesario por ello, que el mediador centre su labor en el proceso de leer como un trabajo en el cual debe ganarse al individuo que se encuentra con la literatura, de tal modo que se enamore de ella.

Es preciso tomar en cuenta los sentimientos de ese lector, siguiendo a Scheler (2003) quien afirma "Amar y odiar, finalmente, constituyen el estadio superior de nuestra vida 
intencional emocional" (p.36), y justo allí queremos anclar la lectura y los textos, al universo emocional de nuestros alumnos, si es posible posicionarlo en una cúspide al punto de considerarlo "una -refiriéndose al texto- admirable máquina de comunicación" (Barker y Escarpit, 1974, p.14).

\section{Hábito y gusto por la lectura}

Un hecho a resaltar en torno a la cultura del libro es que el 9 de noviembre de 1970 la UNESCO decidió designarlo como Año Internacional del Libro, con el firme propósito de atraer la atención de todas las personas hacia el libro ya no como mero objeto sino como ese elemento fundamental cuyo rol esencial en la educación, en la ciencia y en la cultura es la de cambiar a las personas y por ende que éstas puedan cumplir una función determinada en la sociedad. La UNESCO constantemente ha resaltado la trascendencia de los libros como medio para lograr alcanzar los fines y sueños que el sujeto se traza en la vida, más si se trata de países en vías de desarrollo pues la lectura y el libro pueden traducirse como la llave que abre las puertas a las sociedades en proceso de evolución y desarrollo, de allí que Escarpit (1968) vea al último como "un vehículo y no como un monumento" (p.12) haciendo que el lector viaje de manera infinita.

El libro, históricamente ha estado relacionado a la formación y al progreso pues a través de ellos se pueden constatar hechos históricos y otros acontecimientos relacionados con inventos del hombre, es por ello que al hablar del libro es necesario ubicarlo como un instrumento indispensable al momento de emprender el camino a alcanzar nuevos horizontes. No obstante, las sociedades que alcanzan este tipo de éxito como lo es la lectura y el placer por ella han alcanzado la libertad plena pues con ella se viene un proceso reflexivo vital para las sociedades progresistas.

Ciertamente, los medios de comunicación de corte audiovisual han interrumpido en los últimos años el gusto y la pasión por el medio impreso, específicamente los libros y los periódicos, siendo éstos los llamados instrumentos necesarios en la primera etapa de formación del individuo. En este sentido, es necesario acotar que la expansión de la tecnología y las telecomunicaciones en los últimos diez años ha sido si se quiere brutal en todo el mundo, con ello se ha visto afectada la cultura literaria y lectora, justo por eso, Cadenas (2004) menciona "una lengua amenazada" (p. 3); y ello se puede corroborar al ver jóvenes con bajo léxico, hecho contraproducente a nivel escolar pues el contacto con el texto impreso lleva más trabajo cada día cultivarlo en el aula. Claro está, esta reflexión no conduce necesariamente a pensar en internet 
como un medio exclusivamente diseñado para obstaculizar la pasión por los libros, pues en la red se encuentran muchos libros digitales e información vital para los lectores e investigadores.

El libro, cuyo invento data desde hace más de 4000 años se ha convertido en una verdadera máquina con el cual se puede comunicar el mundo entero por medio de la escritura de hombres cuyo legado y testimonios han llegado a estos tiempos gracias a sus libros y escritos, también las traducciones juegan un papel fundamental ya que es necesaria en el momento en se va a leer un libro de otra cultura y de otro idioma que no sea escrito en la lengua materna del lector, a partir de esa lectura los mensajes son cifrados, asimilados y nuevamente interpretados, pues la lectura permite a cada sujeto ser independiente y autónomo según sean sus criterios de selección y análisis.

En tal sentido, Bravo (2009) asegura que "la experiencia de la escritura enriquecerá las posibilidades culturales de la percepción y se extenderá hacia la experiencia de la legibilidad o ilegibilidad del mundo" (p.43); y gracias a este proceso es posible que el sujeto plasme su entorno bien legitimándolo o no debido a su forma de observar y evaluar el mundo.

Estructural y físicamente, el libro ha cambiado con el único objeto de parecerle agradable a quien lo va a leer, esto puede notarse hoy día en las portadas, diseños y dimensiones en la elaboración textual, las editoriales en su carrera por vender y ganar adeptos a la lectura han desarrollado estrategias en la promoción y difusión de libros. Una muestra son los libros de frases célebres, clásicos de la literatura, grandes hombres y los que llaman 'libro de bolsillo' cuyos tirajes se hacen en grandes medidas ya que son puestos a la venta en muchos sitios ajenos a librerías con la intención de que cualquier persona lo vea y posteriormente lo adquiera, teniendo éste la característica principal en su manipulación diaria, la persona puede llevarlo a cualquier sitio al que vaya.

Los hábitos de lectura son más complejos de estudiar de lo que parece, no siempre el comportamiento asumido por una persona revela que ésta sea asidua de dicho proceso, por ende, el maestro y promotor de lectura puede encontrarse en el medio con personas engañosas. Es común en estos días los libros que cumplen un papel hasta pragmático pues resuelven de una manera inmediata aquello que el lector no alcanza a saber pues no ha leído completa la obra literaria, a ellos se les denomina resúmenes literarios. En ese particular, y al no darse un proceso de lectura completa de la obra de arte, será imposible desarrollar eso que Read (1967) conceptualiza de "fuerza vital" (p. 8) y que es la puerta de entrada triunfal con la que ese lector - 
humano según nuestro criterio- logra identificar y asimilar lo más puro que tiene un texto literario, bien sea que esa pureza apunte a una estética de la belleza, la fealdad, el bien o el mal, si existe un espacio en el que una persona pueda percibir las bondades de la vida es precisamente en su equivalente a nivel de la creación humana: el arte y la literatura.

Por otro lado, existe un flagelo que siempre ha atacado la sociedad en torno a los procesos de lectura e interpretación como lo es el analfabetismo funcional, este problema se ve reflejado en una gran cantidad de estudiantes bachilleres que llegan a la universidad con un profundo desconocimiento de las habilidades mínimas de comprensión textual, simplemente se limitan a descifrar códigos presentes en el libro impreso más no a comprender para luego interpretar. Luego de hacer este acto de mera decodificación no se ha dicho más nada puesto que nada ha quedado en él salvo escasos conceptos producto en la mayoría de las veces de un aprendizaje memorístico.

De hecho, la cultura memorística ha sido un gran obstáculo para el desarrollo del pensamiento crítico, de allí que escasee en nuestras aulas interrogantes fundamentales en torno a lo que se asigna como actividad de lectura, no es algo que sea prioritario en un mundo cada vez más abarrotado por la tecnología, como se sabe, con ella se vienen algunos elementos conducentes a la nadería, y si seguimos la idea de Han (2014) quizá el desencanto sea mayor y hasta apocalíptico en el futuro próximo pues ve en la infinita elección actual "la muerte y el perecimiento del amor" (p. 5), muriendo así por extensión la pasión por la lectura y el libro al punto de quedar en una especie de congelamiento histórico.

La buena lectura y un buen ritmo en torno a ella permiten al individuo acceder a un campo de la comunicación eficaz y efectiva, el lector va labrando un terreno que es pensamiento y expresión del mundo alrededor de esas lecturas significativas, elaboradas simultáneamente desde las ideas e imágenes textuales cuya etapa final es la apropiación del libro desde su razonamiento interno, desde su subjetividad. El lector, a partir del principio de apropiación del texto tiene la oportunidad de reconstruir el relato, es como una suerte de ingrediente final que escapa de los autores pues la autonomía de lectura permite a cada sujeto ver nuevos elementos según sea su juicio valorativo y sus horizontes de sentido en tanto sensibilidad del ser ante el arte de leer.

En el mercado de los recetarios y métodos de lectura es posible encontrar recomendaciones para desarrollar el hábito para leer, sólo por mencionar algunas puede tomarse 
en cuenta las que dan cuenta de la necesidad de tener un mediador como lo es el maestro en el aula. Otra vía muy común es la lectura silenciosa solicitada siempre a quienes quieren y desean leer a solas, que aunque privados de lo sonoro viven a lo interno eso que Block de Behar (1974) configura como una "retórica del silencio" (p.11), toda vez que esta omisión de la voz, acústicamente hablando jamás deja de ocultar una revuelta interna de palabras y frases las cuales desencadenan en el lector una explosión que más allá lo literario culmina por iluminar la vida y llenarla de sentidos y direccionalidad.

En fin, la idea de leer silenciosamente nos conduce a valorar más la prudencia, el poder esperar concienzudamente y no adelantarnos a lo que de manera impulsiva puede llevarnos a crasos errores, de allí la importancia de leer, pudiendo así superar obstáculos comunes y escalar más en el terreno del pensamiento crítico.

También han diseñado métodos de visualización de palabra lo cual permite leer más rápido, en fin, sea lenta o acelerada, silenciosa o en voz alta la lectura es el producto de un hecho social muy importante y que permite a la persona trascender social e intelectualmente. En cuanto a métodos, técnicas y estrategias de lectura se ha escrito bastante, sin embargo, podemos citar el clásico abordaje que Blay (1970) realiza en función de la rapidez de la lectura, allí sostiene que dicha velocidad se debe a "las exigencias de la vida profesional y al deseo de una mayor información cultural, estando de ese modo al tanto de muchas cosas" (p.7), siendo esto precisamente lo que le toca a muchas personas, sobre todo a nuestros estudiantes quienes deben cumplir con muchas lecturas y deberes, obviando la mayoría de las veces el principio placentero y gozoso del que hemos venido hablando.

Creo firmemente que más allá de métodos debe hablarse de experiencias y sobre todo de vivencias literarias cuya comprensión amerita la inferencia por parte del lector ya que el lenguaje artístico es ante todo una forma diferente de expresar el arte requiriendo por ende mecanismos distintos de comprensión e interpretación.

El no leer o el abandono de la lectura por parte de algunas personas de debe a factores diversos, la falta de tiempo es un alegato común entre mucha gente, hay quienes habiendo aprobado una carrera de dedican a vivir de los éxitos y no vuelven a leer ya que su época de estudios ha quedado atrás. Otros incluso han leído una determinada obra el cual los condujeron a una especie de trauma psicológico y de profundo rechazo por los libros y la lectura a nivel general. Por último, hay quienes piensan que si no lo hicieron en sus primeros años ya no lo 
harán después de la edad adulta debido a que no tuvieron ese hábito desde niños, a saber, según nuestro punto de vista que no existe una edad para granjearse un hábito de lectura, en el momento que ello ocurra será el más propicio.

A la hora de cultivar el hábito por la lectura es bueno que el individuo haga un equilibrio entre el trabajo y el ocio, si la persona trabaja mucho es necesario que descanse antes de leer pues de lo contrario le generará fatiga y la lectura se debe hacer con el cerebro y el cuerpo en estado de relajación física y emocional. Si bien la fatiga y ciertos malestares representan un obstáculo para el desempeño de ciertos roles más todavía lo es para el acto de leer, aunque existen personas que dicen leer para calmar sus problemas y dolencias pues ésta produce un alivio para quien se siente cansado.

De lo anteriormente expuesto, se dirá ante todo que, la persona debe tener actitud positiva y mucha disponibilidad para crearse un hábito por la lectura, viendo al texto literario como algo que puede proyectarse más allá del contexto escolar, llegando a convertirse en la vida de una persona en una suerte de filosofía de vida, fin último de la lectura libre y proclive a causar el goce del ser.

\section{El libro en la vida del lector}

En Venezuela, al igual que otros países, el libro nuevo ha sido un verdadero artículo de lujo, o por lo menos un artículo reservado para ser adquirido por una minoría con poder adquisitivo. Lo bueno es que algunos planes y programas editoriales del estado han puesto en circulación libros a bajo costo e incluso bibliotecas básicas escolares gratis. Esto de los libros costosos se ha comprobado incluso cuando los padres se quejan al momento de comprar las listas de útiles, incluso es común escuchar lo propio en la universidad por parte de quienes forman el ser de las casas superiores, muchos de ellos culminan haciendo copias de ellos y en última instancia tomándoles fotos con sus aparatos celulares en lugar de adquirir uno original.

En las librerías se pueden ver hasta tres ediciones diferentes de un libro, muchas de ellas acuerdan editar varias presentaciones de un texto para que haya la oportunidad de adquirirlo según sea el capital del comprador. Sin lugar a duda las más caras generalmente de desbordan en detalles de lujo como el material, la portada y hasta datos del autor como una pequeña biografía. En contrapartida, los más económicos hasta llegan a tener sólo el título de la obra y el autor en la portada y muchas veces están escasos de algún prólogo o presentación por parte de un especialista. 
Aunado a la publicación de libros a bajos precios debe ponerse en marcha la difusión y distribución de dichos textos, sobre todo pensando en todas aquellas que no pueden visitar librerías en las ciudades o centros comerciales debido a su ubicación en algún sitio rural. En ese sentido, las distribuidoras tienen y deben colocarlos a la venta en puestos de revistas y periódicos para que ellos estén a la vista y al alcance de todos sin que ello represente una limitante.

En la actualidad son comunes los libros usados, allí se pueden encontrar ejemplares económicos y algunos de vieja publicación que en algunas oportunidades se hacen difíciles conseguir en recientes ediciones, también esto es una forma cónsona a los medios para que el libro llegue a las manos del lector como también lo son estrategias implementadas en los clubes de lectura en el cual funciona el intercambio de libros y experiencias de lectura. En ese particular, se ha visto en las últimas décadas como en toda América Latina se hacen ferias del libro usado, poniéndose en práctica no solamente la venta sino también el trueque entre los asistentes.

Los especialistas en promoción de lectura aseguran que ante todo es primordial el sistema de bibliotecas públicas, para ello es necesario que el estado invierta en la creación de más bibliotecas con lo cual se tenga la opción de ir a consultar libros y tomarlos en préstamos para el hogar y la escuela. En consecuencia, y aunado a la buena disposición de los maestros y bibliotecarios en formar y orientar a los usuarios de las bibliotecas y libros para que de ese modo le den un buen trato a los mismos sin llegar a dañarlos.

\section{El lector en la difusión del libro}

Con el afán de resolver los problemas de lectura, muchos entes gubernamentales, educativos y editoriales se han dado a la tarea de investigar qué leen las personas, todo ello a los fines de publicar y poner en marcha la circulación de libros para dichos gustos. Esto no es una mala estrategia del todo, pero la lectura tiene distintas aristas según el criterio de cada lector ya que un libro en manos diferentes se torna variado por el gusto de cada uno y sus propósitos subjetivos, sólo por mencionar un ejemplo se puede mencionar el clásico de la literatura universal Moby-Dick (1851) de Herman Melville con el cual algunos lectores se podrán mostrar interesados en la pesca de ballenas, otros por las aventuras en el mar y en el caso de los lectores un poco más adultos asumirán el drama personal del Capitán Ahab en su búsqueda obsesiva del feroz animal. 
De esto puede deducirse que el acto de lectura es tan importante como el libro, desde los principios de ambos se desprenden y determinan los gustos por la lectura, desde estas nociones y paralelamente a lo que se lee se debe investigar el cómo y por qué leen las personas. Toda esta labor humana, educativa y pedagógica debe circunscribirse a lo que Bonet (1970) denomina como "una función de belleza que no debe estudiarse como una cosa aislada, sino como un hecho relacionado con un clima social” (p.7), logrando así una fina comunión del arte literario con la sociedad, cuya vitalidad se nutre de cuanto el hombre propone en el mundo.

Cuando se le pregunta a una persona el motivo que le lleva a leer las respuestas son variadas, algunos contestan 'para distraerme', 'por obligación en mis estudios', 'para relajarme', 'para evadir problemas del mundo' y 'para descansar'; entre otras que de seguro tendrán las personas al momento de relacionarse con la lectura. Sería un poco imprudente pensar que algunos de los lectores antes mencionados llegan a la lectura para huir de sus realidades refugiándose en el libro ya que simultáneamente el individuo se está informando, instruyendo y enriqueciendo el espíritu, esto son los milagros de la lectura que tiene una suerte de propiedades curativas.

Si bien para algunas personas la lectura es una suerte espacio para el placer y para otros un acto de preparación e instrucción, en ambos casos se trata de una actividad significativa que proyecta al hombre a otros universos, algunos de ellos paralelos a las realidades que cotidianamente se viven. En torno a lo anteriormente mencionado, pueden evidenciarse los resultados al ver actitudes intelectuales en individuos con profundos contenidos en sus conversaciones y buen manejo de una lengua fluida al mismo tiempo que un uso amplio del vocabulario ya que los libros siempre aportan palabras y expresiones nuevas al léxico de quien lee.

Para acceder a ese espacio de múltiples oportunidades, será necesario alejarse de algunas actividades habituales pues todo ello amerita inversión de tiempo, indudablemente esa lejanía representará una ganancia de tipo artística a la que Blanchot (2002) llamara "soledad esencial" (p. 17); ya que es la manera más expedita y sabia de llegar al arte literario, comprenderlo e interpretarlo.

Estas diferencias entre lectores es lo que hace un poco difícil dejarse guiar por las encuestas, en este sentido puede resaltarse la importancia de todas estas formas de leer pues, alternamente las personas se distraen y se instruyen si lo que leen realmente lo hacen por 
iniciativa y motivación, es más, en el medio educativo es común ver personas que pasan de la lectura por instrucción a la lectura por placer. La lectura motivadora es, infinitamente más frecuente que la lectura obligada ya que los lectores que desean hacerlo acuden constantemente a las bibliotecas, se hacen asiduos lectores de un diario e incluso de varios para ver la perspectiva de cada uno en el manejo de la información. Ya el sólo hecho de acudir voluntariamente a una biblioteca o centro de información y documentación supone una actitud deliberada por parte de quien quiere tener contacto con libros.

Por otro lado, la iniciativa al momento de leer tiene mucho que ver con la selección de lo que se leerá, muchas personas escogen los libros por los temas tratados, por los títulos que les parecen llamativos y motivadores y de algún modo esto resulta una suerte de aliciente y hasta un atractivo para adquirir el texto, resaltando que algunas editoriales basan sus propagandas en el argumento de tener los mejores títulos de los mejores autores.

Sin embargo, es de notoria importancia resaltar que estos elementos antes mencionados son sólo dispositivos y estrategias en el mundo de la lectura, lo más importante será siempre la predisposición de parte del lector, sea éste incipiente o avezado en esa red infinita de los libros. Tal infinitud plantea una búsqueda en la que los lectores descubren una fuente inagotable de experiencias estableciendo lo que Blanchot (2002) aduce como "relación íntima con el saber” (p. 61) cuya luz emanada desde los textos jamás dejará de brillar, seduciendo cada segundo a quien lo toma entre sus manos y más que con ellas con su corazón abierto al mundo de la fícción.

Según investigaciones muy particulares de quien escribe esto, se intuye en el aula la presencia de dos tipos de lectores con patrones diferenciales, uno que pareciera ser objetivo y el otro participativo, en el primer caso el lector se muestra autónomo, mantiene distancias entre él y su lectura la cual se convierte en receptáculo de sus necesidades reales, el segundo se introduce en todos los recovecos del libro, se identifica con los personajes y situaciones como una especie de familiarización entre ambos. Por estas razones, es muy difícil delimitar los problemas en torno a la lectura, tantos gustos y hábitos hay en el mundo como lectores.

Siempre será posible llevar al lector hacia el libro en la medida que éste circule en la sociedad, en algunos países, específicamente en España hacen siempre jornadas para que los lectores además de acudir a ferias tengan oportunidad de tener contacto directo con los escritores quienes son homenajeados y de ese modo las motivaciones y la pasión por la lectura crecen más en cada persona. 


\section{Los libros y su importancia en la educación}

Como toda sociedad, los libros en el contexto educativo juegan un papel muy importante pues permiten el acceso a la instrucción guiada por padres, maestros y promotores de lectura lo cual incide en el proceso de enseñanza y aprendizaje, hecho éste que interesa tanto a países desarrollados como aquéllos en vías de progreso. Hoy día se ha hablado incluso de la desaparición del libro en la escuela, pero esto no es cierto pues sólo se ha propuesto y en algunos planteles se han visto los libros digitales, incluso los audiolibros son en estos días muy frecuentes ya que las personas sólo se dedican a oírlos sin necesidad de hacer algún esfuerzo convencional como lo es la manipulación física de un texto. En este caso, lo que pasa es que el material impreso ha adoptado una forma más compleja y tecnológica el cual se integra a un nuevo conjunto de instrumentos y estrategias de enseñanza.

Todo gobierno debe tener como prioridad la producción masiva de libros escolares para que la educación avance rápidamente, especialmente los libros de primaria y bachillerato que forman los pilares de todo sujeto en período de formación, en materia de literatura infantil y juvenil es imperiosa la necesidad en torna a la difusión de novelas, cuentos y poesías acordes a la edad y el nivel de instrucción, ya este contacto entre lector y texto supone una ganancia para el sistema educativo.

Conjuntamente al vínculo entre lectores y libros en el medio educativo, es necesaria la inversión por parte del estado en mantener una infraestructura acorde a las condiciones en que deben estudiar las personas, las aulas deben tener sus bibliotecas y ambientes cómodos al aprendizaje, hecho éste que facilita el proceso de enseñanza y más específicamente la práctica de la lectura placentera.

Los libros en manos de maestros y alumnos se convierten en un verdadero tesoro que llegan a despertar la pasión por la lectura, esto contribuye enormemente a contrarrestar los vicios de lenguaje que poseen actualmente una gran cantidad de niños y jóvenes en la sociedad a nivel general. Es posible encontrar adultos que juzgan con indiscriminada dureza la capacidad de expresión de estos jóvenes ya que les parece aglutinante y extremadamente pobre su discurso, sin lugar a dudas tienen razón ya que ese estado crítico de la comunicación refleja su estado interior y que a su vez da cuenta del entorno en el cual ha crecido como lo es el hogar y muchas veces la calidad de maestro, esto último es también un problema que ataca a la educación, falta de preparación e iniciativa en algunos maestros para formar ciudadanos. 
Los factores que atentan contra el buen manejo de la lengua son varios, ya se trate de las reuniones juveniles donde generalmente nacen modismos y expresiones estereotipadas cargadas de doble sentido, palabras y consignas que en ciertos casos circulan en las sociedades impuestas por personas del mundo artístico. Así también, onomatopeyas y gestos comunes que finalmente impiden que el sujeto avance en su formación, esto por el contrario lo sumerge en un profundo retroceso ya que cada día se atropella y a la vez deteriora el idioma que en última instancia es el tesoro más grande que puede tener un hablante.

En estos tiempos actuales también es común oír a los adultos criticar la escuela y la educación de hoy día, aseguran que la escuela de antaño era mucho más selectiva y de mayor calidad. Al respecto, debe tomarse en cuenta que no todos los casos en los que un individuo egresa del sistema educativo con malas bases se deben a un factor únicamente, son variadas las causas que las cuales fueron nombradas anteriormente, se trata más bien de comprobar e investigar los hechos, dar con el paradero del por qué no leen, es posible en ese sentido que nunca hayan sido incitados o estimulados a la lectura.

Los libros, finalmente, son un puente entre los lectores y el mundo, allí reposan los grandes autores, la historia de la humanidad con lo cual se erigen las personas en el acto de leer, punto de partida o elemento primordial en ese evento tan importante como lo es la lectura como hecho social complejo. Ya cuando se plantean los procesos de escritura se infiere con anterioridad que ha sido planteado la cuestión de la lectura, son procesos que están hermanados y en constante confluencia, una es variante de otra y ninguna de las dos se dan a la ligera, sino que ameritan esfuerzo y tesón por parte de quien los pone en práctica, al final todo es consecuencia de una insistencia lo cual declina en un capital simbólico y abstracto.

Puede decirse que, de acuerdo con los diferentes problemas en torno al libro y los bajos niveles en los sistemas educativos no se pueden discriminar las lecturas que hagan las personas o estudiantes, que no parezcan erróneas, sin sentido y hasta sin validez ya que cada uno de los textos que pueda y quiera leer una persona llega a tener valor y utilidad lo cual está acorde a sus criterios de selección, tomando en cuenta lo más importante que es propiciarle vida a los libros a partir de la lectura. 


\section{A manera de reflexión}

Este trabajo no ha pretendido en ningún momento recomendar textos ni autores específicos para esas etapas de la vida, más bien se centró en la relación texto-lector y la forma cómo es el encuentro de ambos en la escuela, el hogar y la vida. En ese sentido, la lectura de textos literarios debe dejar un sabor agradable en el niño, adolescente y joven sobre todo si son los primeros libros que lee. De ese modo, quien ha llevado a cabo la labor de promover la literatura debe seguir algunas recomendaciones establecidas por Lomas Pastor (2002) cuando asegura que "el libro no puede estar rodeado de un excesivo aparato crítico ni presentarlo alejado del mundo actual" (p. 229), con lo que el lector puede, aunque la obra sea de corte clásico y date de cien, doscientos o más años, amoldarla a sus necesidades.

Se puede asumir el texto literario como un puente que facilita la imaginación y la creatividad en el niño, pero esto no quiere decir que un maestro, en función de la lectura literaria le solicite al lector crear cuentos, poemas, dramas y otras manifestaciones literarias que en todo caso no le sería fácil o agradable, lo antes descrito guarda más relación con la producción literaria. En la mayoría de los casos, la escritura y la producción literaria de un autor (niño, adolescente, joven o adulto) se corresponde con el hábito de leer y esto a su vez puede traducirse en que el niño que lee puede desarrollar habilidades y destrezas para producir o por lo menos acercarse a la creación literaria, no obstante, el maestro en su rol de promotor invita a la creación literaria partiendo del criterio y la libertad del sujeto.

La literatura, sin lugar a discusión es un arte que permite y facilita el desarrollo del pensamiento creador, en el mundo intelectual a veces el pensamiento de erudición rebasa el pensamiento creador, en ese sentido, el promotor de lectura debe aprovechar una condición innata que tiene el ser humano como lo es la creatividad, de allí que todo sujeto, según sea su inclinación y la pasión por un oficio escoge en la vida un rumbo en el cual invertir sus destrezas y habilidades. Si se tiene en cuenta lo anterior, la lectura literaria sumerge al lector en un estado de ensoñación sin límites y a partir de allí se puede decir que:

El hombre con una imaginación bien desarrollada vive con intensidad el mundo del arte y la literatura, se solaza con rememoraciones de gran fuerza y brillantez, puede ubicarse fácilmente en el papel de otro y comprenderlo, vive con gran intensidad cada experiencia, evita las rutinas y los esquemas, "juega" con las ideas y las imágenes, se permite soñar despierto y predecir el futuro (González Valdés, 2000, p. 14). 
De lo anterior se puede deducir, que la imaginación del niño, si se familiariza con el texto presente en las palabras de la obra literaria, además de propiciar el pensamiento creador y el placer, amplía de manera efectiva los horizontes del lenguaje en el lector y sucesivamente adquiere competencias lingüísticas.

Toda meta alcanzada, en algún momento fue pensada y más que esto imaginada, la lectura de los primeros años en ese particular puede servir de catapulta para que las metas y los ideales se concreten, estas ideas se defienden desde los textos y desde el amor que cada lector construya. Tomando en cuenta ese principio, Ingenieros (2005) sostiene que "la imaginación es madre de toda originalidad, deformando lo real hacia su perfección, ella crea los ideales y les da impulso con el ilusorio sentimiento de la realidad" (p. 9); y cuando el lector se acerca a esa realidad con el deseo de ser mejor, sus sueños e ilusiones ya han trazado un camino señalando un fin o un lugar de llegada.

Cuando esas metas se concretan, también se ha concretado el camino hacia el lenguaje, el lector a lo largo de su estancia en las obras literarias ha examinado desde su interior el mundo alrededor de las palabras, esa experiencia en el cual ha desmenuzado los libros en direcciones distintas y múltiples intereses es lo que lleva a Foucault (1996) a plantear que: "la literatura es un lenguaje al infinito, que le permite hablar de sí misma hasta el infinito" (p. 81); y por ende le permitirá al lector abrir en sí mismo un camino lleno de árboles sempiternos cuyos frutos (palabras, frases, lenguaje, etc.) colgados en las ramas sean variadas y multiformes. Después de todo, seguiremos colaborando para para que maestros y alumnos sean el epítome de la felicidad en tanto lectura voraz y placentera, te toca a ti formularte ¿Por qué leer? y ¿Para qué leer?...

\section{Referencias}

Barker, R. y Escarpit, R. (1974). El deseo de leer. Barcelona, España: Ediciones Península. Barthes, R. (2008). El placer del texto. Argentina: Siglo XXI Editores.

Blanchot, M. (2002). El espacio literario. Madrid: Editorial Nacional.

Blay, A. (1970). Lectura rápida. Barcelona, España: Editorial Iberia.

Block de Behar, L. (1974). Una retórica del silencio. Funciones del lector y procedimientos de la lectura literaria. México, D.F: Siglo Veintiuno Editores.

Bonet, C. (1970). Escuelas literarias. Buenos Aires: Editorial Columba. 
Bravo, V. (2009). Leer el mundo. Escritura, lectura y experiencia estética. Madrid: Ediciones Veintisiete Letras.

Brillat Savarin, A. (1966). Fisiología del gusto. Madrid: Editorial Mediterráneo.

Cadenas, R. (2004). En torno al lenguaje. Caracas: Monte Ávila Editores Latinoamericana.

Carrillo Pimentel, M. Para un acercamiento al asunto la de la lectura: la experiencia de leer y narrar. Trabajo no publicado, Laboratorio de Arte y poética, Universidad de Los Andes, Trujillo. s.f.

Carrillo Pimentel, M. y Carrillo, C. Lectura en tres etapas. Trabajo no publicado, Laboratorio de Arte y poética, Universidad de Los Andes, Trujillo. s.f.

Cervera, J. (1992). Teoría de la Literatura Infantil. España: Ediciones Mensajero. Universidad de Deusto.

Escarpit, R. (1968). La revolución del libro. Madrid: Editorial Alianza.1968.

Fromm, E. (1974). El lenguaje olvidado. Buenos Aires: Editorial de la Librería Hachette.

Foucault, M. (1996). De lenguaje y literatura. Barcelona, España: Ediciones Paidós.

Girard, R. (1985). Mentira romántica y verdad novelesca. Barcelona, España: Editorial Anagrama.

González Valdés, A. (2000). Como propiciar la creatividad. Caracas: Fondo Editorial Tropykos.

Greimas, A. (1973). En torno al sentido. Madrid: Editorial FRAGUA.

Han, B. (2014). La agonía del eros. Barcelona, España: Editorial Herder.

Huizinga, J. (2000). Homo ludens. Madrid: Alianza Editorial.

Ingenieros, J. (2005). El hombre mediocre. Bogotá: Gráficas Modernas.

Lapoujade, M. (1998). Filosofía de la imaginación. México, D.F: Siglo XXI Editores.

Lomas Pastor, C. (2002). Como hacer hijos lectores. Madrid: Ediciones Palabra.

López, R. (1997). El niño y su inteligencia. Caracas: Monte Ávila Editores Latinoamericana.

Lotman, I. M. (1999). Cultura y exposición. Lo previsible e imprevisible en los procesos de cambio social. Barcelona, España: Editorial Gedisa.

Prieto Figueroa, L.B. (2002). La magia de los libros. Barquisimeto: Universidad Pedagógica Experimental Libertador. Instituto Pedagógico Luis Beltrán Prieto Figueroa.

Read, H. (1967). Orígenes de la forma en el arte. Buenos Aires: Editorial Proyección.

Scheler, M. (2003). Gramática de los sentidos. Lo emocional como fundamento de la ética. Barcelona, España: Crítica. 
Schiller, F. (1968). La educación estética del hombre. Madrid: Espasa-Calpe.

Schücking, L. (1969). Sociología del gusto literario. La Habana: Cuadernos de Arte y Sociedad.

Smith, F. (1992). Comprensión de la lectura. Análisis psicolingüístico de la lectura y su aprendizaje. México, D.F: Editorial Trillas.

Trías, E. (1991). Lógica del límite. Barcelona, España: Ediciones Destino.

Tusón, J. (1989). El lujo del lenguaje. Barcelona, España: Ediciones Paidós Ibérica.

Wittgenstein, L. (1988). Investigaciones filosóficas. Instituto de Investigaciones filosóficas de México. Barcelona, España: Editorial Crítica.

Zúñiga García, J. F. (1995). El diálogo como juego. La hermenéutica filosófica de Hans-Georg Gadamer. Granada, España: Publicaciones de la Universidad de Granada. 